\title{
PAPERS
}

\section{Combination of laser treatment and intraluminal radiotherapy for malignant dysphagia}

\author{
E Shmueli, E Srivastava, P J D K Dawes, M Clague, K Matthewson, C O Record
}

\begin{abstract}
Background-Laser treatment for malignant dysphagia is limited by recurrent intraluminal tumour requiring repeated treatment at four to eight week intervals. Aims-To reduce the need for follow up treatment and to improve survival, patients successfully palliated by laser were treated with intraluminal radiotherapy.

Patients-32 patients with inoperable oesophageal carcinoma (18 adeno and 14 squamous cell carcinoma).

Methods-The patients were initially palliated by a median of three laser treatments. They were then treated with intraluminal radiotherapy, receiving 10-15 Gy at $1 \mathrm{~cm}$ from the source as a single treatment with the Selectron system. Patients with squamous cell carcinoma also received external radiotherapy (30 to 50 Gy).

Results-After the radiotherapy nine patients survived a median of 22 (range 4-40) weeks without requiring any further endoscopic treatment. The remaining patients survived a median of 40 (range 4-102) weeks and required a median of three follow up endoscopic treatments over that time. Eleven patients developed fibrous strictures with no intraluminal tumour and were treated by dilatation. Twelve patients required dilatation and repeat laser therapy for a combination of fibrous stricture and recurrent intraluminal tumour. Six patients eventually required Atkinson tubes.

Conclusions-The combination of laser treatment with intraluminal radiotherapy provides good palliation and may reduce the need for repeated endoscopic treatment. Fibrous stricture formation is a common complication.

(Gut 1996; 38: 803-805)
\end{abstract}

Keywords: oesophagus, malignant dysphagia, laser, brachytherapy, selectron.

Endoscopic laser treatment for patients with inoperable oesophageal malignancy may provide reasonable palliation of dysphagia with a low risk of treatment complications. ${ }^{1-3}$ Especially suitable are patients with short exophytic tumours, non-circumferential tumours, and tumours involving the upper oesophagus where intubation with a prosthesis is difficult. ${ }^{1-3}$ However, as only intraluminal tumour is treated by the laser, regrowth of tumour into the lumen often occurs and in most series follow up treatment is required at four to eight week intervals to maintain swallowing. ${ }^{1}$ Thus while intubation is potentially a one session treatment, laser therapy may need repeating on numerous occasions, particularly in longterm survivors.

In this paper we describe patients who after successful palliation by laser photoablation went on to receive intraluminal radiotherapy as a means of treating extraluminal tumour and mural invasion. Patients were treated with intraluminal radiotherapy if laser palliation was successful, intraluminal tumour recurrence considered likely, and their general condition was good, implying the need for considerable future endoscopic therapy.

\section{Methods}

Thirty two patients aged mean (SD) 71 (9) (range 55-83) years received laser therapy and intraluminal radiotherapy. They were considered inoperable principally because of: extensive tumours or metastatic disease (12 with two found to be inoperable at laparotomy); concurrent disease (9); or extreme age (9, mean age 78 (5)), and two patients refused surgery. Table I shows the tumour characteristics. All treatment was carried out with a Neodymium yttrium-aluminium-garnet laser delivering $70-90 \mathrm{~W}$ at $1064 \mathrm{~nm}$ in pulses of 0.5-2 s duration. Patients were sedated with midazolam or diazepam and pethidine. Treatment consisted of dilatation if necessary using Savary-Guilliard dilators to $15 \mathrm{~mm}$,

TABLE I Characteristics of the tumours

\begin{tabular}{|c|c|c|}
\hline & Adenocarcinoma & $\begin{array}{l}\text { Squamous cell } \\
\text { carcinoma }\end{array}$ \\
\hline \multicolumn{3}{|c|}{ Location of upper margin of tumour (n) } \\
\hline $\begin{array}{l}\text { Between } 20 \text { and } 30 \mathrm{~cm} \\
\text { Below } 30 \mathrm{~cm} \text { but without }\end{array}$ & 7 & 4 \\
\hline $\begin{array}{l}\text { involvement of cardia } \\
\text { Below } 30 \mathrm{~cm} \text { with }\end{array}$ & 3 & 10 \\
\hline $\begin{array}{l}\text { involvement of cardia } \\
\text { Length (n) }\end{array}$ & 8 & 0 \\
\hline $\begin{array}{c}\leqslant 5 \mathrm{~cm} \\
6-10 \mathrm{~cm} \\
>10 \mathrm{~cm}\end{array}$ & $\begin{array}{r}4 \\
12 \\
2\end{array}$ & $\begin{array}{r}3 \\
10 \\
1\end{array}$ \\
\hline
\end{tabular}

\author{
Surgery, Newcastle \\ General Hospital \\ M Clague \\ Correspondence to: \\ Dr E Shmueli, Northampton \\ General Hospital \\ Cliftonville, Northampton \\ Accepted for publication \\ 29 December 1995 \\ Gastroenterology \\ E Srivastava \\ C O Record \\ and Radiother \\ Royal Victoria \\ Infirmary, Newcastle \\ Upon Tyne
}


TABLE II Effect of laser treatment on dysphagia

\begin{tabular}{lcc}
\hline Swallowing ability & Before treatment & After treatment \\
\hline Minimal or no difficulty & 1 & 18 \\
Difficulty with solids & 8 & 14 \\
Difficulty with semisolids & 18 & 0 \\
Difficulty with liquids & 5 & 0 \\
\hline
\end{tabular}

followed by laser treatment in a retrograde manner beginning at the lower margin of the tumour. It was not necessary to use the laser in a prograde manner to create a lumen in this series of patients. In most cases treatments were separated by 72 hours to allow necrotic tissue to slough.

Intraluminal radiotherapy was administered using a Selectron (Nucleotron, Veenendaal, the Netherlands) after-loading caesium machine using a technique described by Rowland and Pagliero 4 but under sedation with midazolam rather than general anaesthesia. The procedure entailed endoscopy in which the tumour extent was marked with external metal clips under fluoroscopic control followed by passage of the Selectron catheter over a guidewire. The Selectron catheter is a flexible plastic tube of $8 \mathrm{~mm}$ diameter containing an insert tube to hold caesium beads over a $12 \mathrm{~cm}$ length. An insert tube with dummy beads was initially used and the position of the catheter adjusted so that the dummy beads lay across the tumour. It was fixed with a mask to the patient's face, the insert tube with the dummy beads was removed, and the patient transferred to a shielded treatment room where an empty insert tube was inserted into the Selectron catheter and connected to the Selectron machine. A total of $24 \times 1.48 \mathrm{GBq}$ Caesium-137 sources supplied by Amersham International were loaded pneumatically and distributed over $12 \mathrm{~cm}$ under computer control. No adjustment was made for the length of the tumour. At the midpoint of the source train and $1 \mathrm{~cm}$ from the centre of the source the dose rate was $6.4 \mathrm{~Gy} /$ hour. The patient was monitored by closed circuit

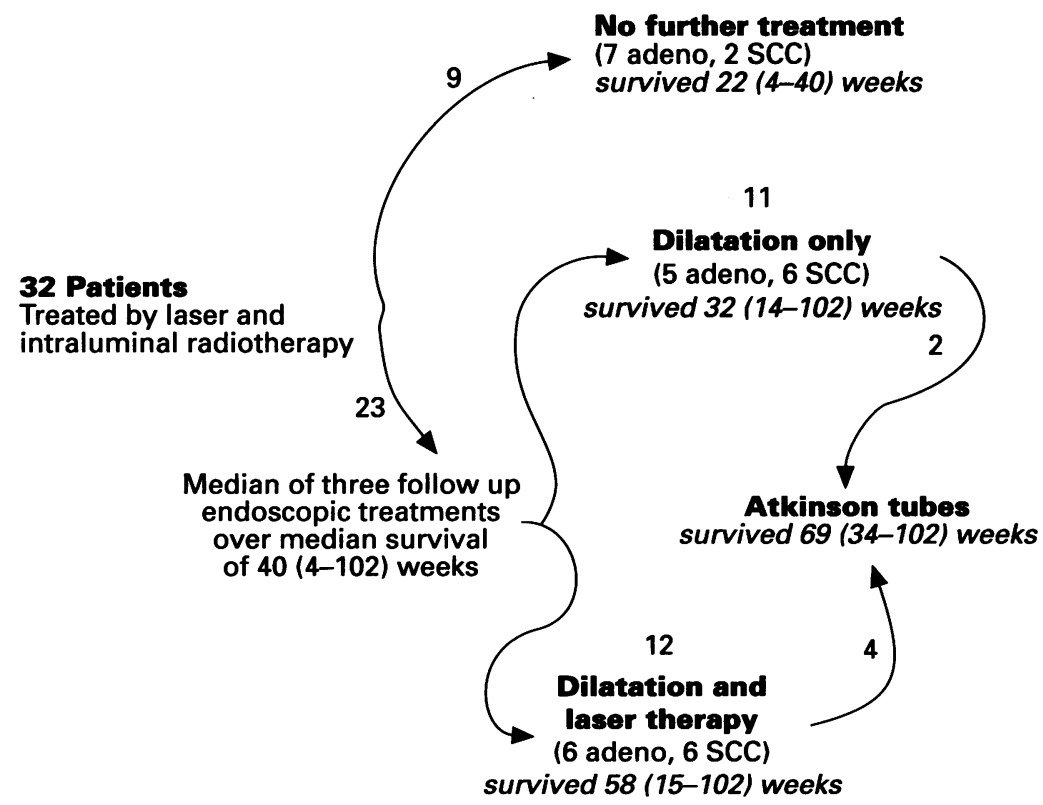

Outcome of patients and survival after selectron therapy. television. The whole procedure takes about two hours. Most patients required an overnight stay in hospital.

The intraluminal radiotherapy was administered one to four weeks after the laser therapy. Those with squamous carcinoma received 10 Gy intraluminally and 30-50 Gy externally in 10 daily fractions. Those with adenocarcinoma received $15 \mathrm{~Gy}$ intraluminally only. It was felt that adenocarcinoma was less sensitive to radiotherapy necessitating a higher local dose, and that little additional benefit would accrue to these patients from external radiotherapy. No routine endoscopic follow up was arranged in most cases; patients were encouraged to contact the unit directly if their symptoms recurred.

\section{Results}

A median of three (range 1-7) laser treatments were required as an initial treatment to relieve dysphagia. These treatments were complicated by two minor oesophageal perforations comprising a pneumomediastinum with minimal constitutional upset that settled with conservative management. Table II illustrates the effect of the treatment and shows that dysphagia improved in all patients (paired $t$ test $p<0.001$ ). After completion of this treatment half of the patients could eat solid food, and all could manage semisolids. The radiotherapy was well tolerated with no complications. Some patients had a minor worsening of their dysphagia, which resolved over a few days.

Overall mean (SEM) survival from diagnosis was 50 (5) weeks with no significant difference between patients with squamous or adenocarcinoma. The mean (SD) requirement for follow up endoscopic therapy was $2.9(0.9)$ treatments for patients with adenocarcinoma, and $2.6(0.6)$ treatments for patients with squamous cell carcinoma. The Figure shows the outcome of the patients and survival after the selectron therapy.

Almost one third of the patients required no further endoscopic treatment to maintain their swallowing until death. One third required dilatation only, and the remaining third required a combination of dilatation and laser treatment. The development of a fibrous stricture was the commonest cause of recurrent dysphagia occurring in $18(56 \%)$ of patients. In some cases the stricture occurred within two weeks of the selectron treatment. In these patients dilatation restored swallowing for prolonged intervals. These strictures were sometimes very tough requiring forceful dilatation. In one case dilatation was complicated by oesophageal perforation and death. In six cases Atkinson tubes were inserted to obviate the need for repeat treatment in patients now getting very frail or because of external oesophageal compression.

\section{Discussion}

Inoperable oesophageal malignancy carries a poor prognosis regardless of the treatment modality used to palliate the dysphagia and survival is usually about six months. ${ }^{5}$ A 
number of treatment modalities is now available singly or in combination and must be tailored to the individual patient. Laser therapy provides excellent palliation for patients with exophytic tumours particularly when the stricture is short or the tumour is non-circumferential. Some relief of dysphagia is apparent after even one treatment session permitting early discharge from hospital. The main disadvantage of laser therapy is the need for repeat therapy at four to eight week intervals because of regrowth of intraluminal tumour. ${ }^{1-3}$

Intraluminal radiotherapy (brachytherapy) has the advantages of delivering a high radiation dose to the tumour, as a single treatment, with little systemic effect. It may relieve dysphagia in a proportion of patients for several months. ${ }^{46}$ However, in some patients transient worsening of the dysphagia occurs for up to a week after therapy because of tissue oedema. ${ }^{6}$ It may not therefore be appropriate as a first measure in patients presenting with severe dysphagia, in whom debulking of the tumour with laser therapy provides rapid palliation.

In combining the treatments exophytic tumour was removed by laser and mural invasion treated by radiotherapy. The aim was to achieve rapid effective relief of dysphagia with laser therapy, and reduce the requirement for follow up laser treatment with intraluminal radiotherapy. This aim was largely achieved as a third of the patients required no further endoscopic therapy at all, and two thirds required a median of three treatments over a median survival of 40 weeks after the Selectron treatment.

This combination has been previously used. Bader $e a^{7}$ used iridium-192 after laser treatment, but six sessions were required over one to two week intervals to permanently relieve the dysphagia. Renwick et $a l^{8}$ used a similar technique to ours but with a rigid oesophagoscope. They also noted a prolonged dysphagia free interval (6 to 65 weeks) and the development of fibrous strictures in four of 20 patients treated. Fibrous strictures seem to be the main drawback of the combined therapy, but they can usually be dealt with by simple dilatation. External beam radiotherapy has also been used as an adjunct to laser photoablation. ${ }^{9}$ Again the combination gave a prolonged dysphagia free interval amounting to nine weeks overall or 17 weeks for the nine patients with squamous cell carcinoma. A third of the patients developed fibrous strictures, and the radiotherapy was poorly tolerated in a number of patients receiving higher doses. We found no significant difference in the response of patients with adenocarcinoma or squamous cell carcinoma unlike Sander et al ${ }^{10}$ who felt that brachytherapy is only useful in squamous cell carcinoma. This may be attributable to a different technique or more probably because we used a higher dose of radiation (15 Gy compared with $7 \mathrm{~Gy}$ at $1 \mathrm{~cm}$ from the source) in the adenocarcinoma patients.

The choice of treatment for inoperable malignant dysphagia must be tailored to the condition of the individual patient. For very frail patients with extensive tumours insertion of a prosthesis as a single measure may be the most appropriate treatment. For other fitter patients more intensive treatment for better palliation of dysphagia is worthwhile. The combination of laser treatment with intraluminal radiotherapy provides good palliation and may reduce the need for repeated endoscopic treatment.

1 Shmueli E, Myzore MF, Burk D, Record CO, Matthewson K. Limitations of laser treatment for malignant dysphagia. Br ₹ Surg 1992; 79: 778-80.

2 Loizou LA, Grigg D, Atkinson M, Robertson C, Bown SG. A prospective comparison of laser therapy and intubation in endoscopic palliation for malignant dysphagia. Gastroenterology 1991; 100: 1303-10.

3 Barr H, Krasner N, Raouf A, Walker RJ. Prospective randomised trial of laser therapy only and laser therapy followed by endoscopic intubation in endoscopic palliation for malignant dysphagia. Gut 1990; 31: 252-8.

4 Rowland CG, Pagliero KM. Intracavitary irradiation in palliation of carcinoma of oesophagus and cardia. Lancet 1985; ii: $981-3$.

5 Sawant D, Moghissi K. Management of unresectable oesophageal cancer: a review of 537 patients. Eur $\mathcal{f}$ Cardiothorac Surg 1994; 8: 113-7.

6 Low DE, Pagliero KM. Prospective randomised clinical trial comparing brachytherapy and laser photoablation for palliation of esophageal cancer. $\mathcal{F}$ Thorac Surg 1992; 104: 173-9.

7 Bader M, Dittler HJ, Ultsch B, Ries G, Siewert JR. Palliative treatment of malignant stenoses of the upper gastrointestinal tract using a combination of laser and afterloading therapy. Endoscopy 1986; 18: 27-31.

8 Renwick P, Whitton V, Moghissi K. Combined endoscopic laser therapy and brachytherapy for palliation of laser therapy and brachytherapy for palliation of Sargeant IR, Loizou LA, Blackman G, Thorpe S, Bown SG. Sargeant IR, Loizou LA, Blackman G, Thorpe S, Bown SG.
Radiation enhancement of laser palliation for malignant Radiation enhancement of laser palliation for malig
dysphagia: a pilot study. Gut 1992; 33: 1597-601.

10 Sander R, Hagenmueller F, Sander C, Riess G, Classen M. Laser versus laser plus afterloading with iridium-192 in the palliative treatment of malignant stenosis of the oesophagus: a prospective, randomized, and controlled study. Gastrointest Endosc 1991; 37: 433-40. 